\title{
Online Delivery of Teaching and Laboratory Practices: Continuity of University Programmes during COVID-19 Pandemic
}

\author{
Kelum A. A. Gamage ${ }^{1, *(1)}$, Dilani I. Wijesuriya ${ }^{2}$, Sakunthala Y. Ekanayake ${ }^{2}$, \\ Allan E. W. Rennie ${ }^{3, *}$, Chris G. Lambert ${ }^{3,4}$ (D) and Nanda Gunawardhana ${ }^{5}$ \\ 1 James Watt School of Engineering, University of Glasgow, Glasgow G12 8QQ, UK \\ 2 Department of Education, University of Peradeniya, Peradeniya 20400, Sri Lanka; \\ dilaniiowa@gmail.com (D.I.W.); syatigammana@yahoo.com (S.Y.E.) \\ 3 Engineering Department, Lancaster University, Lancaster LA1 4YW, UK; c.g.lambert@lancaster.ac.uk \\ 4 Educational Research, Lancaster University, Lancaster LA1 4YW, UK \\ 5 Learning and Teaching Research Group, Sri Lanka Technological Campus, Padukka 10500, Sri Lanka; \\ nandag@sltc.ac.lk \\ * Correspondence: kelum.gamage@glasgow.ac.uk (K.A.A.G.); a.rennie@lancaster.ac.uk (A.E.W.R.)
}

Received: 21 September 2020; Accepted: 15 October 2020; Published: 19 October 2020

\begin{abstract}
A great number of universities worldwide are having their education interrupted, partially or fully, by the spread of the novel coronavirus (COVID-19). Consequently, an increasing number of universities have taken the steps necessary to transform their teaching, including laboratory workshops into an online or blended mode of delivery. Irrespective of the measures taken, universities must continue to maintain their high academic standards and provide a high-quality student experience as required for delivery of learning outcomes associated with each degree programme. This has created a challenge across the higher education landscape, where academics had to switch to remote teaching and different approaches to achieving laboratory delivery. As a result, students have not been receiving face-to-face teaching, and access to laboratory facilities has been limited or nearly impossible. This paper reviews numerous approaches taken by universities to deliver teaching and laboratory practices remotely, in consideration of the COVID-19 pandemic, whilst also considering the potential impacts on the student learning experience. This review is primarily focused on the fields of engineering, science and technology, based on published literature including books, reviewing web-based provision of selected universities, institutional and national policy documents.
\end{abstract}

Keywords: COVID-19; pandemic; higher education; student learning; online delivery; laboratory workshops

\section{Introduction}

In study sectors such as chemistry, physics, engineering, biology, computing, psychology, languages, nursing, medicine, and other allied professions, programme outcomes stress the importance of developing theoretical (content) and practical (processes) aspects. When developing the practical aspects, special emphasis is given to the activities that teach students experimental methods, how to synthesise observations, a range of lifelong and communication skills and laboratory practices.

In December 2019, for the first time, Wuhan City in China officially declared the presence of an unknown virus (now called COVID-19) that soon gained pandemic status, taking many lives around the world (https://www.nature.com/articles/d41586-020-00154-w). The COVID-19 pandemic quickly led to the closure of universities and colleges following the advice of public health officials to maintain social distancing [1]. Consequently, educational institutions quickly adopted e-learning under the 
distance education mode [2,3]. Even though this approach works well for knowledge building through delivering content and oversight of some processes, it has limitations of developing one's practical laboratory skills. For example, if working in a laboratory setting, one would often encounter many types of expensive and complicated instruments and machines. However, operating under a distance learning mode denies valuable hands-on exposure to such facilities and to appreciate the subtleties of being immersed in such an environment. Therefore, it is important to review how universities are currently introducing lab-based practical experiments to students, how they were introduced through online delivery in the pre-COVID-19 period, and what approaches must be taken in the post-COVID-19 period, especially to achieve learning outcomes whilst maintaining a high-quality educational experience.

In this review, we first discuss online teaching and laboratory practices before COVID-19, while summarising examples from published literature. This is followed by presenting the transformation from traditional face-to-face delivery to online delivery, in which we examine technologies used for online delivery, including associated challenges and impacts on assessment practices implemented as a result of COVID-19. There follows a discussion on student experience, highlighting the impacts on their learning experience as well as on their wellbeing. Finally, consideration is made of the policies implemented by educational and other agencies to support universities to uphold quality assurance procedures during online delivery of teaching.

\section{Online Teaching and Laboratory Practices: Pre-COVID-19}

With the advancement of e-learning during the first decade of the 21st century, online approaches have become more widely used in many educational setups [4]. For example, web-based activities are used extensively in distance education courses, whereas blended approaches are used to support teaching and learning activities in campus-based courses. Dantas and Kemm discuss a blended learning approach in which web-based e-learning tools are used to undertake hypothesis testing and predictions prior to the practical class, interpret the results and review the submitted predictions after the class [5]. Goldberg and Dintzis discuss a blended laboratory class carried out at Johns Hopkins University for the 'Organ Systems Histology' course [6]. Pre-laboratory instruction on a web-based overview lecture, a series of web-delivered slide-specific micro-lectures and a set of virtual slides with annotations are introduced to the traditional laboratory experiment.

The class and associated laboratory exercise "Use of PCR for detection of genetically modified sequences in soybean DNA" were discussed in Gibbins, Sosabowski and Cunningham [7]. Two sets of learning materials, manuals for instructor and students (traditional approach), and web-based support centered on a computer aided learning (CAL) package were used for two groups. Both sets of supporting materials were designed to meet the same educational objectives and used descriptive text, static diagrams, and problem-based learning. However, the CAL package has interactive animated diagrams, instant feedback on problems, a hyperlinked glossary, and a simulated optimisation exercise.

An interactive, online dynamic laboratory manual was developed by the Bristol ChemLabS project (www.chemlabs.bris.ac.uk/). The manual incorporates video clips, interactive simulations, formative and summative assessments, and eliminates the need for lab recordings after every class. Some of the complex concepts and techniques can be easily illustrated by videos, which students find a useful resource to prepare them before the actual laboratory work. This also enables students to understand the level of hazards associated with laboratory work as well as to follow safe practices to prevent such conditions.

In a completely different class, Quinn and Robert describe the development of practices of art-making using the internet [8]. They briefly touch on trends in digitally mediated art-making practices, including digital photographic manipulation and collaboration. These art-making methods are important in art education because they increase the possibilities of idea generation and image making for artists in the field, and provide a source of inspiration for students in art classrooms. Such methods for 
eliciting creativity have potential application in subject matter taught in laboratory-based environments where creative thinking is required.

Endean and Braithwaite report a preliminary study carried out to investigate longer-term collaborative working between the Faculties of Science and Maths, Computing \& Technology (MCT) and East China University of Science and Technology (ECUST) in Shanghai, China [9]. The work reported informs a plan to jointly develop an online experiment. The outputs from this preliminary project reveal the similarities and differences in approaches to the development of computer-based experiments in each institution; potential for and challenges in the adaptation of software and hardware for use in both locations; practicable approaches to sharing common facilities for the use of students of either institution; possibilities for creating inter-institution student teams to enhance learning and promote inter-cultural awareness.

The MARVEL project reported by Müller and Ferreira helps to arrange online labs, combined with simulation training and learning-by-doing on real-life systems, in an enriched learning environment [10]. It comprises learning tools or media, learning places and learning activities. The paper gives two examples of online labs, one providing access to a purely remote electronics experiment through LABVIEW and the other one combining remote devices and simulation models in a mixed-reality electro-pneumatics experiment. The equipment and devices used are connected to remote users via the internet. The trials conducted within this project led to conclusions that online labs provide flexible working hours with ubiquitous access and students were able to carry out the real experiments without safety concerns.

\section{Transformation from Traditional to Online Delivery}

It is recognised globally that higher education institutions are highly vulnerable to community transmission of the COVID-19 virus and almost all universities suspended face-to-face academic activities, implementing alternative ways of teaching. One of the techniques adopted by many universities was switching to online delivery. COVID-19 is not the only time universities have switched to online delivery; for example, according to Murphy [1], in Fall (autumn) 2009 some universities switched from face-to-face classes to online delivery during the H1N1 Influenza virus. Further, after Hurricane Katrina's landfall in August 2005, a consortium of 153 colleges and universities reacted quickly to create an online catalogue of more than 1300 courses.

Endean discusses a number of points to be considered when developing online experiments. The author states that it is important to offer virtual experiments while incorporating pictures/data of actual equipment, show good results from real experiments and to connect to real industrial processes [9].

Crawford discusses the responses of higher education institutions in 20 different countries including China, USA, Germany, UK, Singapore, India, and Hong Kong to COVID-19 and how academic programmes were conducted [11]. Even though the paper provides a comprehensive review, no particular information is provided for the delivery of laboratory experiments except mentioning that in Hong Kong, laboratory work was suspended.

\subsection{Technologies}

In the majority of studies described in the previous section, laboratory classes are performed in the real laboratory setups that would not be practical during a pandemic like COVID-19. However, virtual labs, remote control labs or video-based labs are good choices when students are not physically located on campus [12]. For virtual labs, simulation tools and virtual reality are used. Remote laboratories allow the undertaking of experiments through the internet, whereas video-based activities provide a step-by-step overview of a real lab so that students can visualise the whole experimental process and its environment through a video. Zhai, Wang and Liu provide an example for some of the above labs in electrical engineering [12]. According to their findings, the laboratory design enables students to carry out experiments while incorporating autonomous, interactive and collaborative learning of 
electrical engineering experiments. Further, the article states the electrical online laboratory design breaks the space limitation for traditional experimental work and provides a collaborative learning environment where teachers and students can interact and perform laboratory experiments.

Goldberg and Dintzis discuss the steps to implement virtual microscopy via three levels. In the basic level students can be provided with digitised images from a light microscope; this approach is simple to deploy and inexpensive to implement but is limited in terms of functionality [6]. In the intermediate level, a remote-control functionality could be incorporated with a light microscope. When fitted with an electronic stage and focusing controls, a user is able to control the microscope from an offsite location. The more advanced option is to provide slide scanning and virtual microscopy software. This is the most versatile option, but it is an expensive solution as slides are digitised using a slide scanner, and the files are stored on a high-capacity server.

Odeh discusses a remote lab system named the Virtual Instrument Systems In Reality (VISIR) used in the Engineering Faculty at Al-Quds University in Jerusalem, Palestine [13]. VISIR is a remote lab for designing, wiring, and measuring electronic circuits. The user has the ability to access the lab remotely at any location by using the internet. It comprises of a web-based user-interface using any web browser, measurement server, equipment server and switching matrix. The web interface enables the user to perform the same actions as if she/he is in a hands-on lab. The Measurement Server acts as a virtual instructor that controls the commands passing from the web interface to the equipment server to prevent hazardous circuit designs and to protect the instruments. The Equipment Server receives the commands from the Measurement Server to be executed on the real instruments. The Switching Matrix performs the connections between the components and instruments that the user has carried out in the web interface.

Endean lists approximately 160 online experiments delivered as 'simulations', 'virtual experiments', or 'remote control experiments' offered at ECUST in Shanghai [9]. The list covers subjects such as chemistry, physics, chemical engineering, machine principles, controls, computer networking, electrical machines, electrical circuits, transducers, materials engineering, basic mechanical engineering, computer graphics, and monitoring technologies.

A report by Lewis critically reviewed the pedagogical benefits and pitfalls of the increased use of virtual laboratory tools across the Biological Sciences [14]. According to the report, the performance in examinations revealed that the virtual laboratory tools were as equally effective as traditional laboratories in increasing student knowledge and understanding as they facilitate active, enquiry-based learning. Further, their use also overcomes health and safety constraints and ethical issues. The main pitfall of their use is that they do not provide hands-on experience of individual techniques or training in the use of individual items of equipment. Further, students do not gain experience of analysing and interpreting incorrect or uncharacteristic data. Furthermore, the report stresses the importance of integrating high-quality virtual laboratory tools with traditional laboratory sessions within curricula.

Adams states that for online teaching and laboratory practices in the biosciences field, enquiry-based learning (EBL) is often more effective than traditional based learning [15]. Some advantages in the EBL method are recognised as learning by discovery, interacting more effectively with peers and tutors and maintaining students' enthusiasm for laboratory work.

\subsection{Challenges of Online Delivery}

High level aims of experimental work in engineering curricula are: (a) developing experimental, design, problem-solving and analysis skills; (b) developing data-recording and analysis skills; (c) familiarising students with equipment techniques and materials; (d) developing practical skills; (e) developing communication and interpersonal skills; (f) developing technical judgement and professional practice; (g) integrating theory and practice; (h) motivating students [16]. Even though online delivery of practical components may be carefully designed to achieve most of these aims, (c) and (d) may be difficult to achieve through the online mode. Further, aims (a) to (g) are achieved by different approaches such as demonstration, exercise, structured inquiry, open-ended inquiry and 
student-led projects. The online delivery of laboratory experiments can be effectively designed to achieve most of these approaches except certain elements of hands-on, practical exercises.

Online teaching and learning demands reliable resources to get online and a computer, laptop, tablet or a smart phone at home. According to the National Center for Education Statistics (USA), only $87 \%$ of U.S. households own or use a computer at home and where only $77 \%$ had access to the Internet [17]. It also reported that the United States had higher percentages of students with computer and internet access in comparison with other countries. This clearly highlights the scale of the challenge of reaching every single student during an online delivery mode. An article by Mezzacappa and Wolfman-Arent stated, "to ensure equity, remote instruction should not be provided to students, including through the internet, technology at home, by phone, or otherwise" [18].

With the spread of COVID-19, Lanka Education and Research Network (LEARN) is providing uninterrupted connectivity to students and academic, research and support staff of research and education institutions in Sri Lanka. The University Grants Commission (UGC) and Telecommunication Regulatory Commission of Sri Lanka (TRCSL) has come to an agreement with network providers in Sri Lanka to provide free access to University Learning Management System (LMS) for the academic community during the period of the COVID-19 outbreak [19].

\subsection{Impacts on Assessment}

Assessment is the measurement of learning that comprises measuring knowledge, skills, and abilities of a student. Assessment normally has two components: formative assessment through continuous means and summative assessment as mid- or end-of-semester examinations. With the outbreak of COVID-19, the end-of-year or end-of-semester examinations in the northern hemisphere had been cancelled or suspended by many examining bodies, with a knock-on impact in the southern hemisphere [20]. In some universities, personalised online examinations were held.

Khan discusses the assessment techniques that can be used when delivering a module through synchronous or asynchronous modes [21]. Out of different techniques such as assignments, Assessment Portfolios, Multiple Choice Questions, Open Book Exams, Objectively Structured Practical/Clinical Examination and Viva Voces, only the last two options are available for assessment of laboratory examinations. However, both these options require a good internet connection between the examiners and students as the requirement is that they be carried out synchronously.

Related to the assessment process, online evaluation has become one of the most concerning aspects of the COVID-19 pandemic for two reasons. First, educators should redesign their on-site evaluation in order to meet distance learning and assessment requirements. Secondly, it is unclear how to ensure that students follow the instructions and do not use additional material (deemed to be inappropriate) in their evaluation tests without the direct supervision of teachers [22]. The paper also discusses four methods that can be used for assessment: linear tests (which require all students to take the same assessment in terms of the number and order of items during a test session); computer adaptive test-CAT (which allows dynamic changes for each test item based on previous answers of the student); Multiple Choice Questionnaires (in which a single correct answer must be chosen from a pool of possible answers shown by the system); Open Answer Tests (in which the statements include at least one parameter that will change its value with each execution of the application). Even though most of these assessment methods work for online delivery of content, it is difficult to use them for online delivery of practice. However, Open Answer Tests can be used with customised parameters to minimise student plagiarism and misconduct.

\section{Student Experience}

The COVID-19 outbreak has disrupted learning activities and the university life of students, and introduced anxiousness about when life will return to "normal". Even though face-to-face teaching is now substituted by online options, very little has been done to fulfil the myriad of opportunities provided by university life for entertainment, leadership, socialising, community engagement, etc. 
During the university closure and lockdown, students may be developing feelings of fear, stress, worry, and isolation. Many universities are providing online help for students to overcome these feelings. For example, the University of Melbourne advises students to move to activities that they can do while staying at home so as to continue learning, such as maintaining studies, reading a book, listening to a podcast, trying out a new hobby or skill, starting a virtual book or movie club, joining an online group or peer forum, etc. [23]. In addition, students will have plenty of opportunities to expand their education. There are a good number of options such as Coursera, FutureLearn, and edX available for one to pick from, develop skills and acquire knowledge.

There is a high probability of graduating some of the COVID-19 cohort of students without adequate laboratory skills and practice; they may be at a long-term disadvantage, compared to those who studied "normally," when they move to another level of study or enter the labour market [20].

The opportunities to obtain collaborative learning experiences enhance the effectiveness of learning. Müller and Ferreira report how online labs allow students to work together as peers, applying their combined knowledge to the solution of a problem and to test and refine their understanding [11]. Furthermore, they pointed out how the interactions among students provide opportunities to acquire various soft-skills, such as the ability to work in teams and to achieve objectives in co-operation with others and to integrate the know-how of others in order to accomplish a given task. Online delivery through a solely asynchronous mode at best hampers and at worst denies most of the above opportunities.

\section{Quality Assurance}

For quality assurance, benchmarking is used to identify examples of excellence and best practice, and then these examples are used as the standard of comparison. Ensuring quality in online education is not primarily a question of IT support, but of academic strategy and educational design. Oliver states that the successful application of e-learning depends on such aspects as the scope and nature of the learning materials, appropriate selection of the learning design and resources and the manner in which it is delivered and supported [24]. These elements can be isolated and identified for benchmarking purposes.

The European Association for Quality Assurance in Higher Education published a document with standards and indicators for quality assurance for e-learning courses [25]. It states that the institutional policies for e-learning may include the constituent elements of quality such as institutional support, course development, teaching and learning, course structure, student support, faculty support with compulsory e-learning training for new members of staff, technological infrastructure, student assessment (learner authentication, work authorship and examination security) and certification, and electronic security measures.

The UK Quality Assurance Agency (QAA) issued a set of guidelines for Practice and Lab-based Assessment [26]. QAA has developed this guidance with their members and sector bodies for the benefit of the UK higher education community. It recognised that often there exists an element of psychomotor skill and competence involved in using or manipulating equipment and states that the method of assessment of these can be modified so that it can take place remotely. The alternative methods that can be used for remote assessments include presenting students with datasets and asking them to interpret them, using remote simulations such as an experiment being conducted in a video presentation where students can see the data being produced and finding programming tasks that can be undertaken remotely rather than in a laboratory. The QAA document also states that such remote assessment methods should consider the degree to which the learning outcomes assess skill and competence in the use of equipment, and if the learning outcomes require the demonstration of laboratory skills using laboratory equipment, then those assessments have to be postponed. However, if the competence in handling equipment has already been demonstrated elsewhere in the course, then even if such a skill is listed as a learning outcome of the module, the assessment of that particular competence can be ignored. 


\section{Discussion}

Several of the key issues for online methods of laboratory and workshop-based learning have been identified and discussed. Perhaps one of the most profound is the student experience, referred to, often universally, as a stalwart of higher education programmes. Many university promoters lament that the student experience is made worthwhile by the presence of people in the place of campuses. Laboratories might well be viewed through the lens of one of these communities within a community. This raises the question of the importance of culture and environment in the learning experiences of students; the accidental, serendipitous, casual encounters in which bonds are formed with peers and learning is convivial will be replaced. It is important that these connections amongst learners are not eradicated and that they persevere as a pivotal part of any good programme, in a different format. The social development of group cohesion, trust, respect, and belonging in order to build a community of learning [27] will be one that we have a responsibility to maintain, no doubt using ingenuity and innovative approaches to establish and build connections.

As Garrison states: "cohesion and sense of belonging are essential attributes in a community of inquiry" [28]. The student experience of the near future will require universities to respond differently to the challenges bought about by COVID-19. Universities will have to continue to think carefully about how provision for well-being is delivered. Laboratories contribute substantially to the social development of scientists and engineers where the exogenous relationships formed with others teach the life skills required in communication and teamwork. In a world where less face-to-face interaction is being actively encouraged, this poses a risk to students who may find it too easy to become even more disengaged with their peers and networks. The exacerbation of isolation can be mitigated by the blending of in-person teaching with high quality online learning: the latter is a place where the interactivity of the learner with others is more important than ever. This will help ensure the student experience continues to be a major distinguishing feature and developmental benefit of university education.

Effective university teachers will, in the future, alter their methods of instruction to support high quality learning and engagement that is enriching. The goal here is to seize the opportunity of reaping benefits, which include customised training, increasing engagement in learning, use of multimedia, acceleration of expertise through scenarios, and learning through digital games [29]. All of these have potential application in laboratory-based training. In attempting to elicit such benefits, teachers themselves will be subject to significant learning both in a move to different pedagogic approaches as well as needing to become expert users in the technologies employed. Acquainting themselves with the pedagogic theory of online-learning is the first step and many are doing this; such a transition needs to be followed by enacting best practice such as the five-step approach to e-moderating model [30] put forward by Salmon. The use of certain methods such as discussions can help students interrogate, reflect on and revise their ideas [31].

As the plethora of challenges emerge in a post COVID-19 era, naturally many are looking to technology to provide large parts of the response and to feature heavily in the future of distance learning. Some advocates view technology as the panacea that has enabled large portions of the developed world to work and learn remotely. Indeed, we have described earlier how solutions utilising cutting-edge virtual reality technology have been shown to be remarkably well-placed to help deliver remote sessions for laboratories. Access to the internet, however, is far from equal across the globe, and some commentators have argued that its access should be a basic human right [32], but with $19 \%$ of individuals in the least-developed countries accessing the internet [33], the pandemic has brought into clear focus existent inequality. Having materials and strategies for teaching via distance learning post COVID-19 is only the second half of the battle; the first is to ensure our learners have the infrastructure to be able to access the content, via the internet. 
Author Contributions: Conceptualisation, K.A.A.G.; methodology, K.A.A.G., D.I.W. and S.Y.E.; formal analysis, D.I.W. and S.Y.E.; investigation, D.I.W.; resources, N.G.; writing-original draft preparation, D.I.W., K.A.A.G., S.Y.E. and C.G.L.; writing - review and editing, A.E.W.R. and C.G.L.; supervision, K.A.A.G.; project administration, K.A.A.G., N.G. and A.E.W.R.; All authors have read and agreed to the published version of the manuscript.

Funding: This research received no external funding.

Conflicts of Interest: The authors declare no conflict of interest.

\section{References}

1. Murphy, M.P. Covid-19 and emergency e Learning: Consequences of the securitization of higher education for post-pandemic pedagogy. Contemp. Secur. Policy 2020, 41, 492-505. [CrossRef]

2. Study.eu Team. Impact of COVID-19 on Studying Abroad in Europe: OVERVIEW. 19 May 2020. Available online: https://www.study.eu/article/impact-of-covid-19-on-studying-abroad-in-europe-overview (accessed on 15 August 2020).

3. Morgan, H. Best Practices for Implementing Remote Learning during a Pandemic. Clear. House A J. Educ. Strateg. Issues Ideas 2020, 93, 135-141. [CrossRef]

4. Rodriguesa, H.; Almeida, F.; Figueiredo, V.; Lopes, S.L. Tracking e-learning through published papers: A systematic review. Comput. Educ. 2019, 136, 87-98. [CrossRef]

5. Dantas, A.M.; Kemm, R.E. A blended approach to active learning in a physiology laboratory-based subject facilitated by an e-learning component. Adv. Physiol. Educ. 2008, 32, 65-75. [CrossRef] [PubMed]

6. Goldberg, H.R.; Dintzis, R. The positive impact of team-based virtual microscopy on student learning in physiology and histology. Adv. Physiol. Educ. 2007, 31, 261-265. [CrossRef] [PubMed]

7. Gibbins, S.; Sosabowski, M.H.; Cunningham, J. Evaluation of a Web-based Resource to Support a Molecular Biology Practical Class_Does Computer-aided Learning Really Work? Biochem. Mol. Biol. Educ. 2003, 31, 352-355. [CrossRef]

8. Quinn, R.D. E-Learning in Art Education: Collaborative Meaning Making Through Digital Art Production. Art Educ. 2011, 64, 18-24. [CrossRef]

9. Endean, M.; Braithwaite, N. Online Practical Work for Science and Engineering Students-A Collaborative Scoping Activity between the UK Open University and East China University of Science and Technology. Available online: http://www.open.ac.uk/about/teaching-and-learning/esteem/sites/www.open.ac.uk.about. teaching-and-learning.esteem/files/files/ecms/web-content/2012-08-Mark-Endean-final-report.pdf (accessed on 10 August 2020).

10. Müller, D.; Ferreira, J.M. Online labs and the MARVEL experience. Int. J. Online Eng. 2005, 1, 1-5.

11. Crawford, J.; Butler-Henderson, H.; Rudolph, J.; Glowatz, M.; Burton, R.; Malkawi, B.; Magni, P.; Lam, S. COVID-19: 20 countries' higher education intra-period digital pedagogy responses. J. Appl. Learn. Teach. 2020, 3, 1-20.

12. Zhai, G.; Wang, Y.; Liu, L. Design of electrical online laboratory and E-learning. In Proceedings of the 2012 International Conference on Future Computer Supported Education, Seoul, Korea, 22-23 August 2012; pp. 325-330.

13. Odeh, S.; Alves, J.; Alves, G.R.; Gustavsson, I.; Anabtawi, M.; Arafeh, L.; Jazi, M.; Arekat, M. A Two-Stage Assessment of the Remote Engineering Lab VISIR at Al-Quds University in Palestine. IEEE Rev. Iberoam. De Tecnol. Del. Aprendiz. 2015, 10, 175-185. [CrossRef]

14. Lewis, L.D. The Pedagogical Benefits and Pitfalls of Virtual Tools for Teaching and Learning Laboratory Practices in the Biological Sciences; The Higher Education Academy: Heslington, UK, 2014.

15. Adams, D.J. Current Trends in Laboratory Class Teaching in University Bioscience Programmes. Biosci. Educ. 2009, 13, 1-14. [CrossRef]

16. Davies, C. Laboratory and Practical Work in the Engineering Curriculum. Learning and Teaching in Laboratories; The Higher Educational Academy Engineering: Heslington, UK, 2008.

17. KewalRamani, A.; Zhang, J.; Wang, X.; Rathbun, A.; Corcoran, L.; Diliberti, M.; Zhang, J.; Synder, T.D. Student Access to Digital Learning Resources Outside of the Classroom (NCES 2017-098); U.S. Department of Education, National Center for Education Statistics,: Washington, DC, USA, April 2018. Available online: https://nces.ed.gov/pubs2017/2017098.pdf (accessed on 7 October 2020). 
18. Mezzacappa, D.; Wolfman-Arent, A. Hite Clarifies Ban on 'Remote Instruction' during Shutdown. Available online: https:/thenotebook.org/articles/2020/03/18/philly-schools-forbid-remote-instructionduring-shutdown-for-equity-concerns/ (accessed on 15 June 2020).

19. LEARN. LEARN's Support for the Challenges of COVID-19. Available online: https://www.ac.lk/covid-19 (accessed on 5 July 2020).

20. Daniel, J. Education and the COVID-19 pandemic. Prospects. Available online: https://doi.org/10.1007/ s11125-020-09464-3 (accessed on 15 September 2020).

21. Khan, R.A.; Jawaid, M. Technology Enhanced Assessment (TEA) in COVID 19 Pandemic. Pak. J. Med Sci. 2020, 36. [CrossRef] [PubMed]

22. Gonzalez, T.; de la Rubia, M.A.; Hincz, K.P.; Comas-Lopez, M.; Subirats, L.; Fort, S.; Sacha, G.M. Influence of COVID-19 Confinement in Students' Performance in Higher Education. Available online: https://arxiv.org/ ftp/arxiv/papers/2004/2004.09545.pdf (accessed on 5 June 2020).

23. University of Melbourne. Coronavirus (COVID-19): Managing Stress and Anxiety. Available online: https://services. unimelb.edu.au/counsel/resources/wellbeing/coronavirus-covid-19-managing-stress-and-anxiety (accessed on 5 June 2020).

24. Oliver, R. Quality assurance and e-learning: Blue skies and pragmatism. Res. Learn. Technol. 2005, 13, 173-187. [CrossRef]

25. Huertas, E.; Biscan, I.; Ejsing, C.; Kerber, L.; Kozlowska, L.; Ortega, S.M.; LaurI, L.; Risse, M.; Schörg, K.; Seppmann, G. Considerations for Quality Assurance of E-Learning Provision. Available online: https://enqa.eu/ indirme/Considerations\%20for\%20QA\%20of\%20e-learning\%20provision.pdf (accessed on 15 June 2020).

26. QAA. COVID-19: Thematic Guidance-Practice and Lab-Based Assessment. Available online: https://www.qaa. ac.uk/docs/qaa/guidance/covid-19-thematic-guidance-work-based-learning.pdf?sfvrsn=e3cecd81_8 (accessed on 25 June 2020).

27. Kreijns, K.; Kirschner, P.A.; Jochems, W. Identifying the pitfalls for social interaction in computer-supported collaborative learning environments: A review of the research. Comput. Hum. Behav. 2003, 19, 335-353. [CrossRef]

28. Garrison, D.R. E-Learning in the 21st Century: A Framework for Research and Practice; Taylor \& Francis: Abingdon, UK, 2011.

29. Clark, R.C.; Mayer, R.E. E-Learning and the Science of Instruction: Proven Guidelines for Consumers and Designers of Multimedia Learning; John Wiley \& Sons: Hoboken, NJ, USA, 2016.

30. Salmon, G. E-moderating. In Encyclopedia of Distance Learning, 2nd ed.; IGI Global: Hershey PA, USA, 2009; pp. 890-897.

31. Ellis, R.A.; Goodyear, P.; O'Hara, A.; Prosser, M. The university student experience of face-to-face and online discussions: Coherence, reflection and meaning. Res. Learn. Technol. 2007, 15, 83-97. [CrossRef]

32. Reglitz, M. The Human Right to Free Internet Access. J. Appl. Philos. 2020, 37, 314-331. [CrossRef]

33. International Telecommunication Union. Measuring Digital Development: Facts and Figures 2019; ITU Publications: Geneva, Switzerland, 2019.

Publisher's Note: MDPI stays neutral with regard to jurisdictional claims in published maps and institutional affiliations.

(C) 2020 by the authors. Licensee MDPI, Basel, Switzerland. This article is an open access article distributed under the terms and conditions of the Creative Commons Attribution (CC BY) license (http://creativecommons.org/licenses/by/4.0/). 